\title{
Tribological properties of short carbon fibers reinforced epoxy composites
}

\author{
Nay Win KHUN ${ }^{1}$, He ZHANG ${ }^{1}$, Lee Hoon LIM $^{1}$, Chee Yoon YUE ${ }^{1}$, Xiao HU ${ }^{2}$, Jinglei YANG ${ }^{1, *}$ \\ ${ }^{1}$ School of Mechanical and Aerospace Engineering, ${ }^{2}$ School of Materials Science and Engineering, Nanyang Technological University, \\ 50 Nanyang Avenue, Singapore 639798, Singapore
}

Received: 26 November 2013 / Revised: 07 January 2014 / Accepted: 14 February 2014

(C) The author(s) 2014. This article is published with open access at Springerlink.com

\begin{abstract}
Short carbon fiber (SCF) reinforced epoxy composites with different SCF contents were developed to investigate their tribological properties. The friction coefficient and wear of the epoxy composites slid in a circular path against a steel pin inclined at $45^{\circ}$ to a vertical axis and a steel ball significantly decreased with increased SCF content due to the solid lubricating effect of SCFs along with the improved mechanical strength of the composites. The scanning electron microscope (SEM) observation showed that the epoxy composites had less sensitive to surface fatigue caused by the repeated sliding of the counterparts than the epoxy. The tribological results clearly showed that the incorporation of SCFs was an effective way to improve the tribological properties of the epoxy composites.
\end{abstract}

Keywords: epoxy composite; short carbon fiber; friction; wear

\section{Introduction}

Polymers are one of the most successfully exploited materials due to incredible variety of chemical structures available and their relatively low cost, ease of processing, acceptable thermal and environmental resistances and recyclability [1]. Generally, polymers have to show good wear resistance in order to be suitable for tribological applications. However, polymers have low-load carrying capacity and short running life when they are employed in tribological applications at high speed under heavy load [2]. In addition, wear of polymers contributes to a significant finical loss in industry [3].

Nowadays, a tremendous interest is increasingly raised in scientific and industrial communities to apply polymer composites for tribological applications such as gears, cams, wheels, bearings, seals and high wear and scratch resistant flexible risers because the specific development of polymer composites based on con-

* Corresponding author: Jinglei YANG.

E-mail: MJLYang@ntu.edu.sg ventional polymers can obtain new materials with new structural and functional properties superior to those of pure polymers [4-7]. Moreover, the tribological properties of polymer composites can be tailored using carbon fillers such as carbon nanotubes (CNT), carbon fibers $(\mathrm{CF})$, graphene and so on [6]. However, some carbon fillers such as CNTs still have drawbacks for the development of CNT reinforced polymer composites due to their high cost and difficult dispersion in polymer matrices [6,7]. Short carbon fibers (SCF) are one of the most popular candidates for the development of structural and functional SCF reinforced polymer composites because of their high surface-to-volume ratio, outstanding thermal, mechanical and electrical properties and good dispersion in polymer matrices [8, 9]. Zhong et al. [10] reported that SCFs were found to improve wear resistance of poly (ether ether ketone) (PEEK) based composites by carrying a main load between contact surfaces and protecting polymer matrices from severe abrasion. Normally, an injection of fiber reinforced polymer composites is in a process of great expansion [11, 12]. Manufacturing of abrasive polymer composites is 
not very attractive because molds manufactured with metallic filled polymer composites exhibit limited durability due to their extensive wear during filling injection stage of the abrasive polymer composites [11,12]. Liquid epoxy resins exhibit better mixing and processing abilities with reinforcement materials in granular or fiber form and the mixtures result in composite materials with intermediate properties depending on combined actions of the components. Although the mechanical properties of SCF reinforced epoxy composites such as tensile and compressive strengths, hardness and elastic modulus have been widely investigated, the reports on the tribological properties of the epoxy composites such as friction coefficient and scratch and wear resistances are not satisfactorily enough. An understanding of a correlation between the SCF content in epoxy composites and their tribological properties is importantly essential for successful tribological applications.

In this study, epoxy composites with different SCF contents were prepared. The mechanical properties of the epoxy composites such as hardness and Young's modulus were measured with micro-indenter. The tribological properties of the epoxy composites, such as friction coefficient and wear, were investigated by sliding against a steel pin inclined at $45^{\circ}$ to a vertical axis and a steel ball.

\section{Experiment details}

Epoxy resin (Epolam 5015, Axson) was mixed with SCFs (M-2007S, Kreca) at different concentrations in a glass beaker and mechanically stirred at 1,500 rpm for $30 \mathrm{~min}$ in a water bath at $60{ }^{\circ} \mathrm{C}$. After degassing for $20 \mathrm{~min}$ in a vacuum oven, hardener (Epolam 5015, Axson) was added in the mixture followed by hand stirring for $10 \mathrm{~min}$ and degassing for another $15 \mathrm{~min}$. The well mixed resin was then slowly poured into the Fixiform cup mold (Struers) and cured at room temperature $\left(\mathrm{RT} \sim 22-24{ }^{\circ} \mathrm{C}\right.$ ) for $24 \mathrm{~h}$. The samples were demoded and post-heat treated at $80{ }^{\circ} \mathrm{C}$ for another $16 \mathrm{~h}$ for the following analysis and testing. The average diameter and length of the SCFs used were about $14.5 \mu \mathrm{m}$ and $90 \mu \mathrm{m}$, respectively.

The surface morphology and topography of the samples were studied using scanning electron microscopy (SEM, JEOL-JSM-5600LV) and surface profilometry (Talyscan 150, Taylor Hobson) with a diamond stylus of $4 \mu \mathrm{m}$ in diameter. For SEM measurement, the samples were coated with a gold layer to avoid charging. Three measurements on each sample were carried out to get an average root-meansquared surface roughness, $R_{\mathrm{q}}$.

The hardness and Young's modulus of the samples were measured using a micro-indenter (micro-CSM) with a pyramidal shaped diamond tip of $20 \mu \mathrm{m}$ in diameter. The indentation test was performed in a load control mode with a total load of $3 \mathrm{~N}$. In each indentation test, the loading and unloading rates and dwelling time at the peak load were $6 \mathrm{~N} / \mathrm{min}, 6 \mathrm{~N} / \mathrm{min}$ and $5 \mathrm{~s}$, respectively. The hardness and Young's modulus of the samples were derived using Oliver \& Pharr's method and average values were taken from sixteen indentation measurements carried out at different locations on each sample [13].

The tribological properties of the samples were investigated using a micro-tribolometer (CSM) by sliding against a $\mathrm{Cr} 6$ steel pin inclined at $45^{\circ}$ to a vertical axis or a Cr6 steel ball in a circular path of $3 \mathrm{~mm}$ in diameter for about 40,000 laps at a sliding speed of $3 \mathrm{~cm} / \mathrm{s}$ under normal loads of 2 and $6 \mathrm{~N}$. The diameters of the steel pin and ball were about $6 \mathrm{~mm}$. All the samples were polished using 1,200 grit papers prior to tribological test. Two to three measurements per sample were carried out to get an average friction coefficient. The widths and depths of wear tracks of the samples were measured using surface profilometry to get average wear width and depth with 4 measurements per wear track.

\section{Results and discussion}

Figure 1 shows the $R_{\mathrm{q}}$ values of the mechanically polished epoxy composites with different SCF contents. The $R_{\mathrm{q}}$ value of the epoxy is about $2.32 \mu \mathrm{m}$. The $R_{\mathrm{q}}$ value of the epoxy composites almost linearly increases from 3.47 to $6.24 \mu \mathrm{m}$ with increased SCF content from 2.5 to $7.5 \mathrm{wt} \%$ although they are mechanically polished under the same conditions. It indicates that the higher SCF content gives rise to the rougher surfaces of the epoxy composites during the mechanical polishing because the increased SCF content increases the numbers of protruded SCFs above the surface and SCF debonded sites on the surface. However, the 


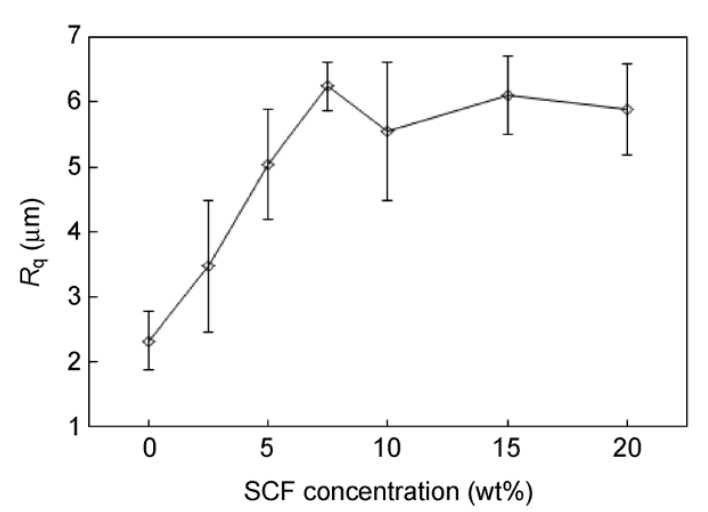

Fig. 1 Root-mean-squared surface roughness $\left(R_{\mathrm{q}}\right)$ of epoxy composites as a function of SCF content.

further increased SCF content more than $7.5 \mathrm{wt} \%$ does not further significantly increase the $R_{\mathrm{q}}$ value of the epoxy composites probably due to the enhanced uniform distribution of incorporated SCFs so that the epoxy composite with $20 \mathrm{wt} \% \mathrm{SCF}$ has the smaller $R_{\mathrm{q}}$ value of about $5.89 \mu \mathrm{m}$ than the one with $7.5 \mathrm{wt} \%$ SCFs. It is clear that all the polished epoxy composites possess the rougher surfaces than the polished epoxy.

Figure 2 shows the surface topographies of the epoxy and epoxy composites with different SCF contents. In Fig. 2(a), the epoxy possesses a relatively smooth surface topography that is composed of small surface asperities although abrasive lines resulted during the mechanical polishing are apparently found on the surface. As shown in Fig. 2(b), the incorporation of $5 \mathrm{wt} \%$ SCFs apparently roughens the surface of the epoxy composite with protruded SCFs and SCF debonded sites. In addition, the possible aggregation of SCFs can also contribute to the rougher surface topography of the epoxy composite with $5 \mathrm{wt} \% \mathrm{SCFs}$. When the SCF content is further increased to $20 \mathrm{wt} \%$ through $10 \mathrm{wt} \%$, the increased numbers of protruded SCFs and SCF debonded sites promote the surface roughness of the epoxy composites as found in Figs. 2(c) and 2(d).

Figure 3 presents the hardnesses and Young's moduli of the epoxy and epoxy composites with different SCF contents. The hardness and Young's modulus of the epoxy are about $200.5 \mathrm{MPa}$ and $3.25 \mathrm{GPa}$, respectively. The hardness and Young's modulus of the epoxy composites significantly increase from about 256.89 $\mathrm{MPa}$ and 4.08 GPa to about $317.16 \mathrm{MPa}$ and $5.26 \mathrm{GPa}$, respectively, with increased SCF content from 2.5 to $7.5 \mathrm{wt} \%$ and then slightly to $352.84 \mathrm{MPa}$
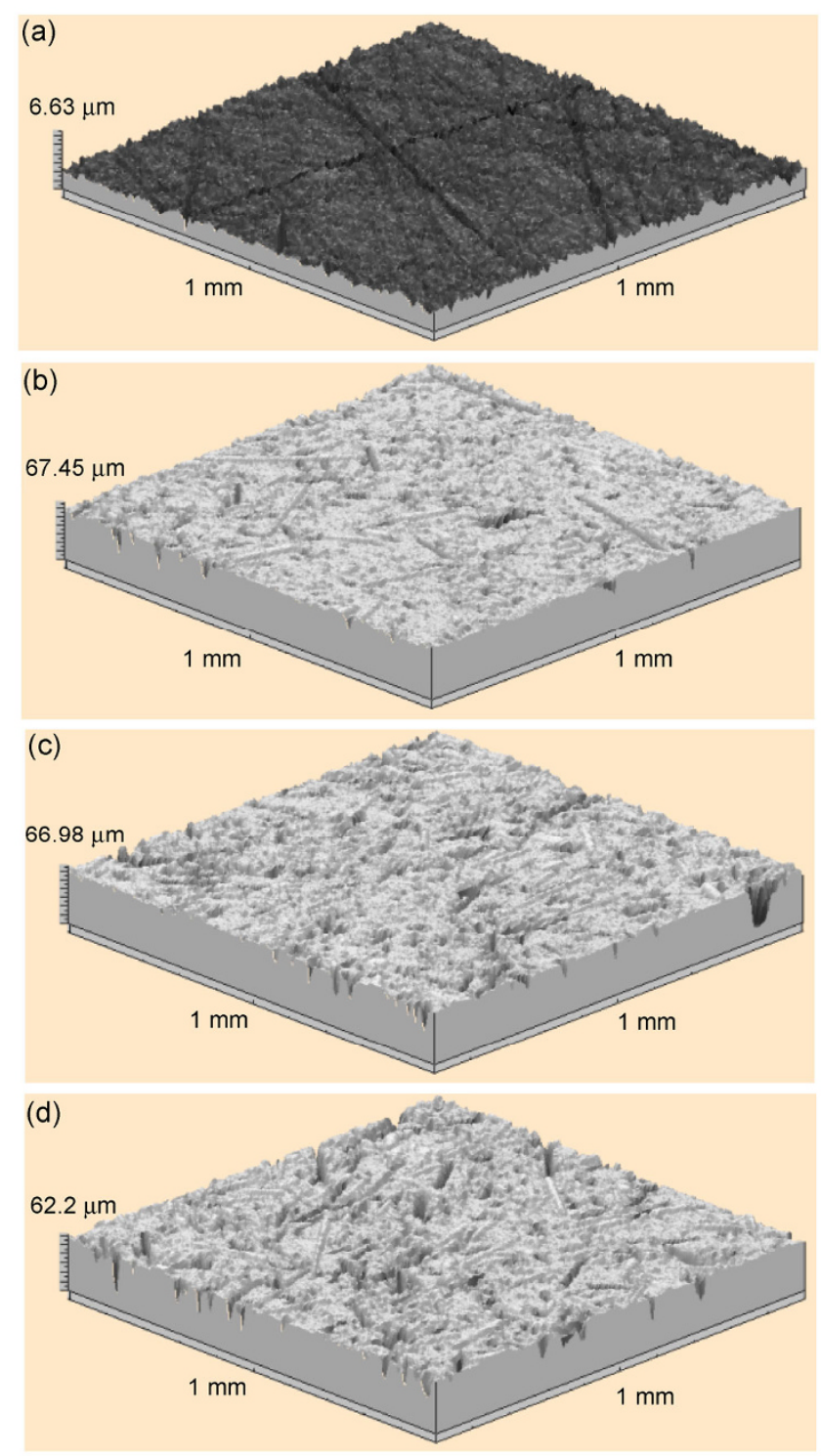

Fig. 2 Surface topographies of epoxy composites with SCF contents of (a) 0 , (b) 5, (c) 10, and (d) $20 \mathrm{wt} \%$.

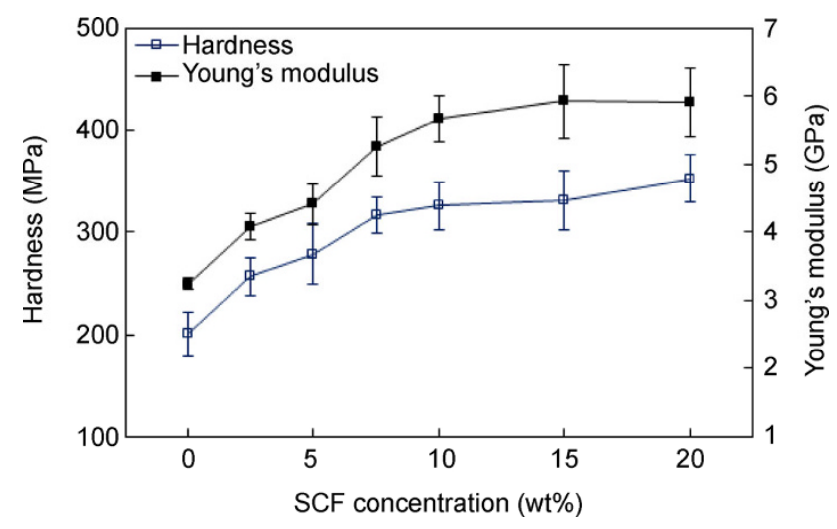

Fig. 3 Hardness and Young's modulus of epoxy composites as a function of SCF content. 
and $5.92 \mathrm{GPa}$, respectively, with further increased SCF content to $20 \mathrm{wt} \%$. It indicates that the incorporation of SCFs in the epoxy matrix apparently improves the hardness and elastic modulus due to the much higher rigidity of the SCFs than that of the epoxy matrix [14-17]. Beyond the SCF content of $7.5 \mathrm{wt} \%$, significant slowdowns in the increased hardness and Young's modulus of the epoxy composites with increased SCF content indicate that the SCF contents more than $7.5 \mathrm{wt} \%$ cannot further give rise to significant improvements in the hardness and elastic modulus of the epoxy composites.

The tribological properties of the epoxy composites were investigated by sliding against a Cr6 steel pin of $6 \mathrm{~mm}$ in diameter inclined at $45^{\circ}$ to a vertical axis because the inclined steel pin could behave as a V-shaped counterpart to generate scratch-induced wear on the surfaces of the composites (see the inset in Fig. 4(a)). Figure 4(a) presents the friction coefficients of the epoxy composites with different SCF contents slid against an inclined steel pin in a circular path of $3 \mathrm{~mm}$ in diameter for about 40,000 laps at a sliding speed of $3 \mathrm{~cm} / \mathrm{s}$ under normal loads of 2 and $6 \mathrm{~N}$.

The mean friction coefficient of the epoxy slid against the inclined pin under a normal load of $2 \mathrm{~N}$ is about 0.67 . The increased normal load to $6 \mathrm{~N}$ slightly decreases the mean friction coefficient of the epoxy to about 0.61 . The sliding of a steel counterpart on a polymer can cause localized softening or melting of the polymer so that the molten materials can be transferred onto the surface of the counterpart to form a transfer layer [18-20]. The transferred polymer layer can reduce the friction coefficient by changing the rubbing mode from the metal-on-polymer to the polymer-on-polymer during the sliding [21-25]. It is supposed that the increased normal load to $6 \mathrm{~N}$ increases frictional heat during the sliding and subsequently reduces the friction coefficient of the epoxy by promoting the transfer of epoxy materials onto the surface of the inclined pin. During the sliding, a possible occurrence of adhesion between two smooth surfaces in contact can give rise to a high friction via an effective interfacial shear strength between the two contacting surfaces $[26,27]$. It can be seen that the higher wear of the epoxy associated with the higher normal load of $6 \mathrm{~N}$ results in the higher surface
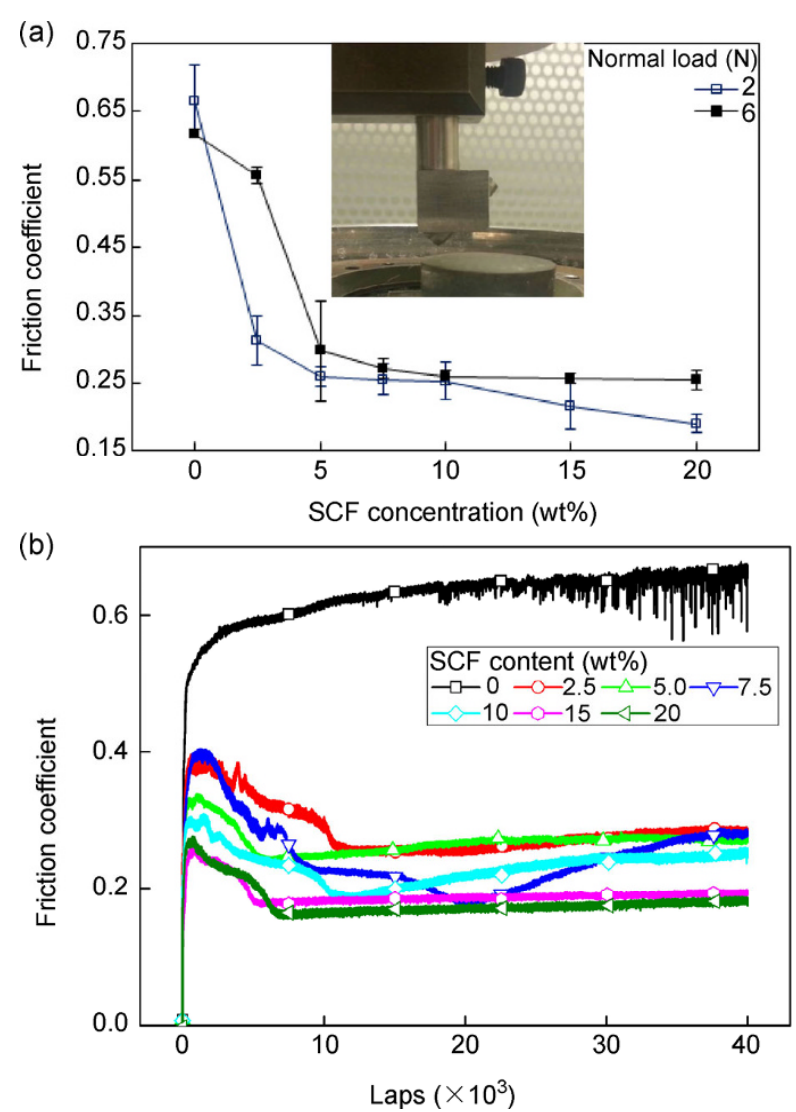

Fig. 4 (a) Friction coefficient of epoxy composites, slid against a Cr6 steel pin of $6 \mathrm{~mm}$ in diameter inclined at $45^{\circ}$ to a vertical axis in a circular path of $3 \mathrm{~mm}$ in diameter for about 40,000 laps at a sliding speed of $3 \mathrm{~cm} / \mathrm{s}$ under different normal loads, as a function of SCF content. (b) Friction coefficient of the same samples, measured under a normal load of $2 \mathrm{~N}$, as a function of the number of laps. The inset in (a) shows a photograph of a holder with an inclined steel pin.

roughening and the larger quantity of wear debris, which in turn lower the friction coefficient of the epoxy by weakening the interfacial shear strength between the inclined pin and epoxy [28, 29]. However, such a decrease in the friction coefficient with increased normal load is not found for the epoxy composites. In addition, the epoxy composites exhibit the higher friction coefficients for all the SCF contents under the higher normal load of $6 \mathrm{~N}$ than under the lower normal load of $2 \mathrm{~N}$. It is known that an incorporation of carbon fillers in a polymer improves the thermal stability of the polymer due to the much higher thermal conductivity of carbon fillers than that of the polymer matrix [30-35]. Therefore, the improved thermal stability of the epoxy composites with the incorporation of SCFs prevents the transfer of surface 
materials onto their counterpart surfaces by dissipating the frictional heat within the matrices [30-35]. Under this condition, the improved hardness and Young's modulus of the epoxy composites (Fig. 3) enhance the sensitivity of the composites to abrasive wear caused by the sliding of the inclined steel pin so that the higher abrasive wear of the epoxy composites associated with the higher normal load results in the higher friction coefficient of the composites through the larger contact area between the steel pin and composite [36-39].

In Fig. 4(a), the incorporation of $2.5 \mathrm{wt} \%$ SCFs apparently lowers the mean friction coefficients of the epoxy composite tested under the normal loads of 2 and $6 \mathrm{~N}$ to about 0.31 and 0.56 , respectively, compared to those of the epoxy. The further increased SCF content from 5 to $20 \mathrm{wt} \%$ further decreases the mean friction coefficients of the epoxy composites from about 0.26 to 0.19 for the normal load of $2 \mathrm{~N}$ and from about 0.3 to 0.25 for the normal load of $6 \mathrm{~N}$. It is known that carbon fillers can serve as a solid lubricant to lubricate the rubbing surfaces [21-25]. Therefore, the increased SCF content leads to the significantly decreased friction coefficient of the epoxy composites (Fig. 4(a)) by promoting the solid lubricating effect of SCFs.

Normally, a larger contact between a polymer and its counterpart can give rise to a higher friction coefficient during sliding [36-39]. Therefore, the existence of SCFs on the surface can lower the friction coefficient of the epoxy composite by lessening a direct contact between the inclined pin and composite. During the sliding, the surface wear of the epoxy composite releases SCFs to an interface between the inclined pin and composite and the released SCFs would freely roll or slide under a lateral force for reducing the friction coefficient of the composite [40]. It is therefore supposed that the increased SCF content decreases the friction coefficient of the epoxy composites due to the reduced contact between the inclined pin and composite and the promoted free-rolling effect of the SCFs in addition to the solid lubricating effect of the SCFs.

Generally, the mechanical strength of a polymer has a significant influence on its friction coefficient and wear [41,42]. The poor mechanical strength of a polymer can result in the higher friction coefficient of the polymer by promoting the contact between the polymer and its counterpart and the wear of the polymer attributed to micro-plastic deformation and micro-cutting caused by the surface asperities of the counterpart [41, 42]. The increased hardness and elastic modulus of the epoxy composites with increased SCF content (Fig. 3) can be therefore correlated to the decreased friction coefficient of the composites since the harder epoxy composites can have the lower friction coefficients by preventing their deformation, lessening their contact with the inclined pin and resisting to their wear.

The effect of surface roughness on the friction coefficient of the epoxy composites should be taken into account since a rougher surface can give a higher friction coefficient via mechanical interlocking between two mating asperities [36-39]. However, no correlation between the increased surface roughness (Fig. 1) and decreased friction coefficient (Fig. 4(a)) of the epoxy composites clearly indicates that the effect of surface roughness on the friction coefficient of the epoxy composites in terms of mechanical interlocking is not significant in this study. On the other hand, the increased surface roughness contributes to the decreased friction coefficient of the epoxy composites by lessening a real contact area between the inclined pin and composite [36-39].

In Fig. 4(a), the epoxy composite with $2.5 \mathrm{wt} \%$ SCFs exhibits a significant increment in the friction coefficient with increased normal load from 2 to $6 \mathrm{~N}$. At the low SCF content of $2.5 \mathrm{wt} \%$, a continuous impact of the inclined pin against protruded SCFs can give a high friction coefficient during the sliding by enlarging a tangential force that is indicative of a frictional force [43]. As a result, an increase in the normal load results in a significant increment in the friction coefficient of the epoxy composite via the pronounced impact of the inclined pin against the protruded SCFs. However, such increments in the friction coefficients of the epoxy composites with SCF contents more than $2.5 \mathrm{wt} \%$ are not found in Fig. 4(a) because the densely, uniformly distributed SCFs over the composite surfaces lessen the impact of the inclined pin against them.

Figure 4(b) shows the friction coefficients of the epoxy composites with different SCF contents, tested under a normal load of $2 \mathrm{~N}$, as a function of the number of laps. The friction coefficient of the epoxy reaches about 0.58 after 3,000 laps and slightly increases with increased laps due to the promoted surface wear 
of the epoxy so that the friction coefficient of the epoxy at the 40,000 laps is about 0.67 . The fluctuation in the friction coefficient of the epoxy becomes significant with prolonged sliding, which is indicative of the pronounced stick-slip phenomenon with the promoted wear of the epoxy [44,45]. The friction coefficient of the epoxy composites first increases with increased laps in the running-in period and turns to decrease before becoming stable for the rest as found in Fig. 4(b). As the trends of friction coefficient versus laps of the epoxy composites are much lower than that of the epoxy, the increased SCF content further depresses the trends of friction coefficient versus laps of the epoxy composites as a result of the further decreased friction coefficient of the composites during the entire sliding.

Figure 5 shows the wear widths and depths of the epoxy and epoxy composites with different SCF contents measured against the inclined pin for about 40,000 laps under the normal loads of 2 and $6 \mathrm{~N}$. The wear widths and depths of the epoxy composites are much smaller than those of the epoxy as well as significantly decrease with increased SCF content, indicating that the increased SCF content results in the dramatically decreased wear of the epoxy composites due to the solid lubricating effect of SCFs along with the improved hardness and elastic modulus of the composites [21-25, 40, 46-50]. Although the epoxy has a decrease in the friction coefficient with increased normal load (Fig. 4(a)), the wear width and depth of the epoxy increase (Fig. 5), which confirms that the increased wear of the epoxy with increased normal load is responsible for its decreased friction coefficient by promoting the surface roughening and the production of wear debris [28, 29]. However, the epoxy composites exhibit increases in their both friction coefficient and wear with increased normal load (Figs. 4(a) and 5), implying that the frictional behavior of the epoxy composites is closely related to their wear behavior as a result of the increased contact between the inclined pin and composite [36-39]. Increments in the wear width and depth of the epoxy composite with $2.5 \mathrm{wt} \%$ SCFs with increased normal load (Fig. 5) are not as significant as an increment in its friction coefficient (Fig. 4(a)) because the increased normal load pronounces the impact of the inclined

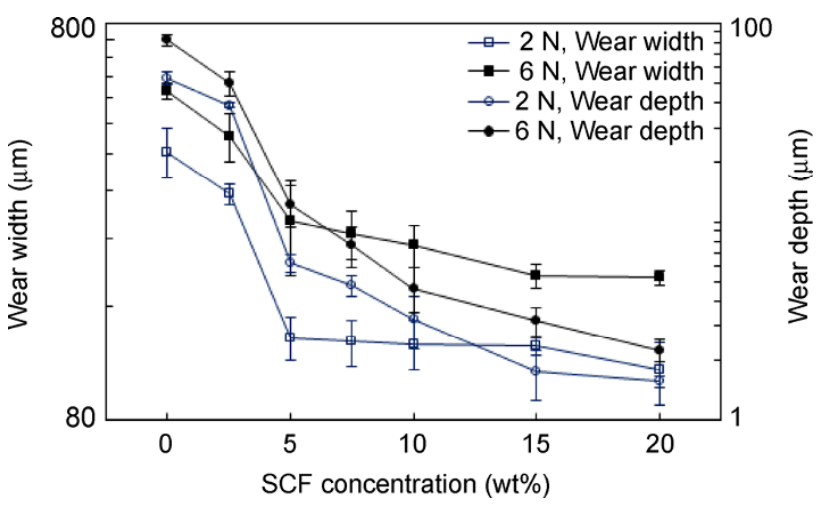

Fig. 5 Wear width and depth of epoxy composites, tested under the same conditions as described in Fig. 4, as a function of SCF content.

pin against protruded SCFs on the surface without giving a very much difference in the wear rates of the composite under the both normal loads.

The surface morphologies of the epoxy and epoxy composites with different SCF contents before and after the tribological test were observed using SEM. Figures 6(a) and 6(b) show the surface morphologies of the mechanically polished epoxy and epoxy composite with $20 \mathrm{wt} \%$ SCFs, respectively. In Fig. 6(a), the mechanically polished epoxy exhibits significant abrasive lines on the surface. It is clearly seen in Fig. 6(b) that the mechanical polishing apparently flattens SCFs on the surface of the epoxy composite with $20 \mathrm{wt} \%$ SCFs via their wear while the debonding of SCFs is found on the same surface. The epoxy composite with $20 \mathrm{wt} \% \mathrm{SCF}$ possesses the rougher surface morphology at the lower magnification than the epoxy (insets in Fig. 6) since the surface of the epoxy composite is apparently covered by SCF debonded sites (inset in Fig. 6(b)), which is also confirmed by the observation of SCF debonded sites on the surface topography of the same composite with the larger $R_{\mathrm{q}}$ value than that of the epoxy (Figs. 1 and 2(d)).

Figures 7(a) and 7(b) and the inset in Fig. 7(a) show the surface morphology and topography of the worn epoxy, respectively, slid against the inclined pin for about 40,000 laps at a sliding speed of $3 \mathrm{~cm} / \mathrm{s}$ under a normal load of $2 \mathrm{~N}$, on which a V-shaped wear track is found. Comparison of Fig. 7(a) and 7(c) clearly shows that the sliding of the inclined pin on the epoxy under the higher normal load of $6 \mathrm{~N}$ generates a larger wear track on the surface due to the higher wear of the epoxy. Micro-wave features are apparently 

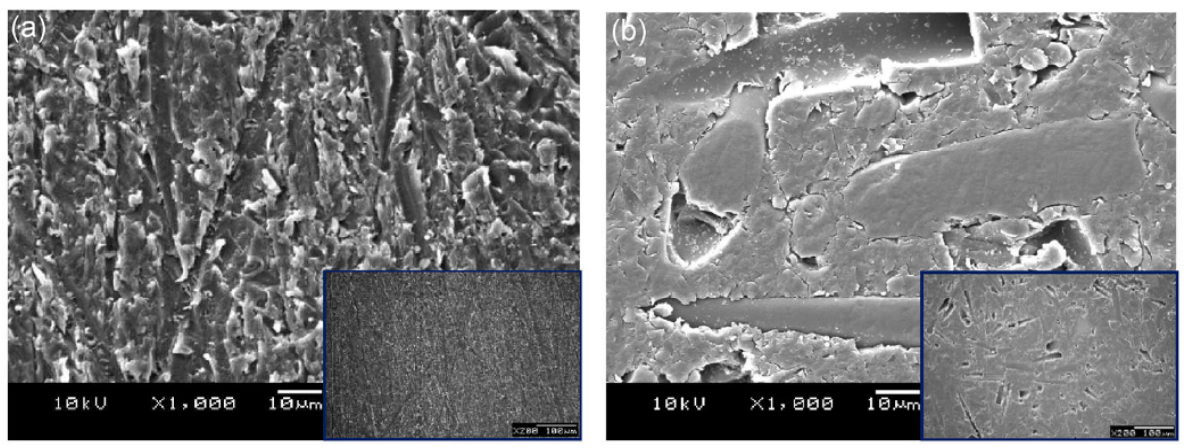

Fig. 6 SEM micrographs showing surface morphologies of mechanically polished (a) epoxy and (b) epoxy composite with 20 wt $\%$ SCFs using 1,200 grit papers. The insets in (a) and (b) show surface morphologies of the same samples at a lower magnification.
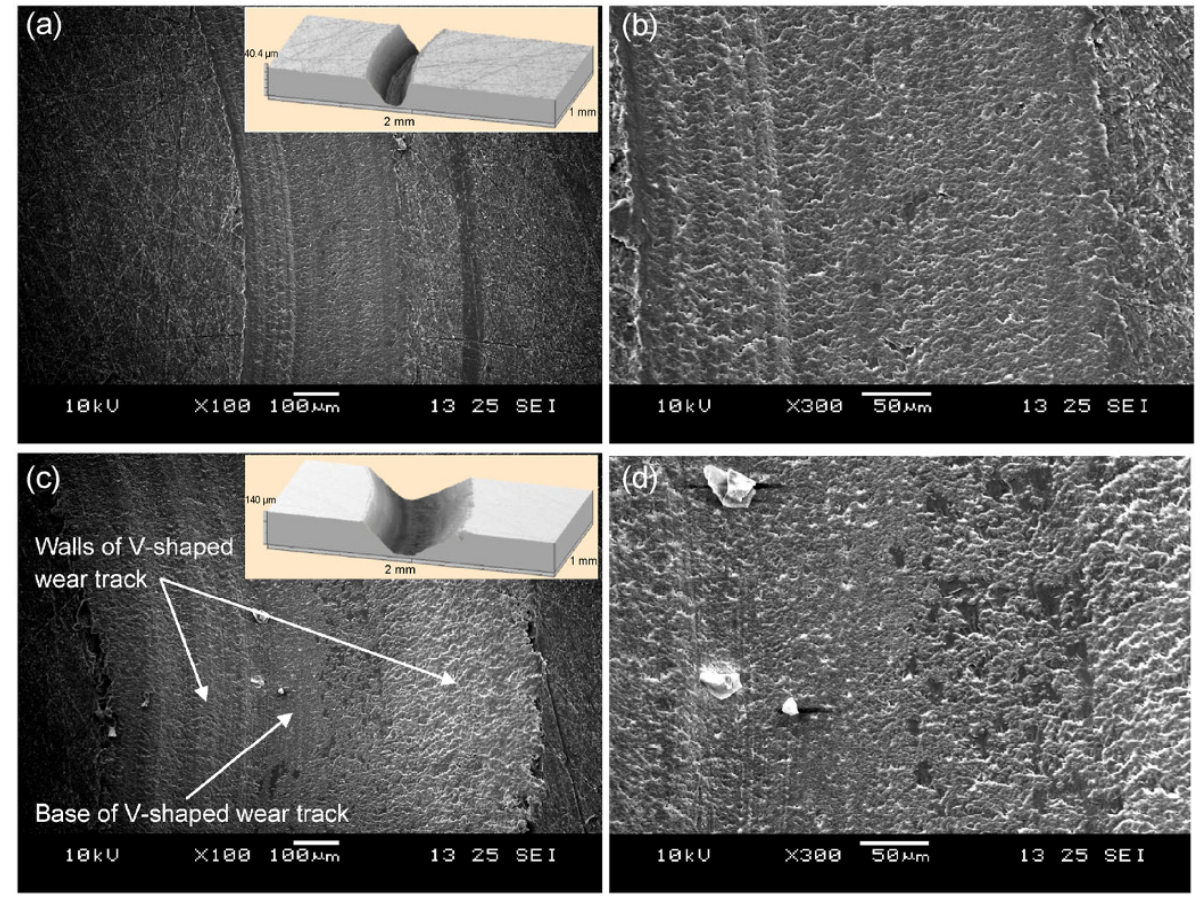

Fig. 7 SEM micrographs showing surface morphologies of worn epoxy, slid against a Cr6 steel pin of 6 mm in diameter inclined at $45^{\circ}$ to a vertical axis in a circular path of $3 \mathrm{~mm}$ in diameter for about 40000 laps at a sliding speed of $3 \mathrm{~cm} / \mathrm{s}$ under normal loads of ((a) and (b)) 2 and ((c) and (d)) $6 \mathrm{~N}$, observed at different magnifications. The insets in (a) and (c) show surface topographies of the same samples measured using surface profilometry.

found on the wear tracks of the epoxy tested under the both normal loads of 2 and $6 \mathrm{~N}$ (Figs. 7(b) and $7(d)$ ), which is indicative of surface fatigue caused by the repeated sliding of the inclined pin. A cyclic stress concentration occurred in front of the inclined pin under cyclic loading causes surface fatigue which initiates minute cracks perpendicular to the sliding direction and propagates the cracks into the subsurface of the epoxy [51,52]. The formation of a network of micro-cracks creates micro-wave features on the wear tracks of the epoxy as found in Figs. 7(b) and 7(d). It is also found that the repeated sliding of the inclined pin induces surface fatigue on the walls of the V-shaped wear track with an apparent appearance of micro-wave features as seen in Figs. 7(a) and 7(c).

Figure 8 shows the surface morphologies of the worn epoxy composite with $20 \mathrm{wt} \%$ SCFs tested under different normal loads. The V-shaped wear tracks of the epoxy composite with $20 \mathrm{wt} \%$ SCFs tested under the normal loads of 2 and $6 \mathrm{~N}$ (Fig. 8) are much smaller 

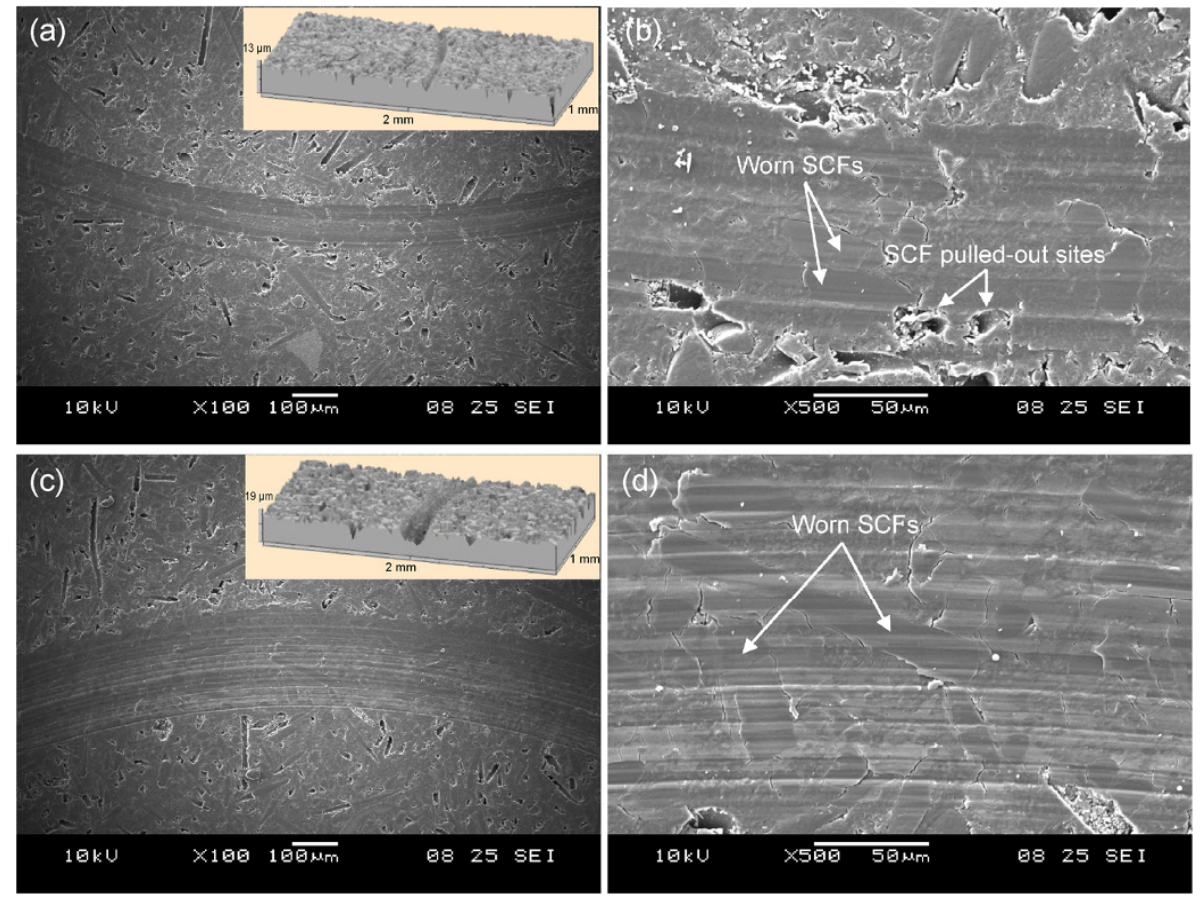

Fig. 8 SEM micrographs showing surface morphologies of worn epoxy composite with $20 \mathrm{wt} \%$ SCFs, slid against a Cr6 steel pin of $6 \mathrm{~mm}$ in diameter inclined at $45^{\circ}$ to a vertical axis in a circular path of $3 \mathrm{~mm}$ in diameter for about 40000 laps at a sliding speed of $3 \mathrm{~cm} / \mathrm{s}$ under normal loads of ((a) and (b)) 2 and ((c) and (d)) $6 \mathrm{~N}$, observed at different magnifications. The insets in (a) and (c) show surface topographies of the same samples measured using surface profilometry.

than those of the epoxy (Fig. 7), which indicates that the incorporation of $20 \mathrm{wt} \%$ SCFs dramatically reduces the scratch-induced-wear of the epoxy composite. As shown in Figs. 8(b) and 8(d), worn SCFs are apparently found on the wear tracks of the epoxy composite, which implies that the existence of SCFs on the surface effectively prevents the scratch-induced wear of the epoxy composite by serving as a solid lubricant to lubricate the rubbing surfaces, lessening a direct contact between the inclined pin and composite and preventing an easy removal of epoxy materials with their much higher wear resistance. In addition, micro-wave features observed on the wear tracks of the epoxy (Figs. 7(b) and 7(d)) are not found on the wear tracks of the epoxy composite with $20 \mathrm{wt} \% \mathrm{SCFs}$ (Figs. 8(b) and 8(d)), indicating that the incorporation of SCFs effectively lessens surface fatigue by preventing a direct contact between the inclined pin and composite under cyclic loading. However, microcracks still can be found along the interfaces between the SCFs and epoxy matrix because the cyclic stress concentration occurred in front of the inclined pin forms interfacial cracks via an occurrence of debonding between the
SCFs and epoxy matrix. SCF pulled-out sites on the wear tracks of the epoxy composite with $20 \mathrm{wt} \%$ SCFs (Figs. 8(b) and 8(d)) suggest that the removal of SCFs from the epoxy matrix during the sliding contributes to the wear of the epoxy composite. Abrasive lines on the wear tracks of the epoxy composite (Figs. 8(b) and 8(d)) imply that the wear of the epoxy composite is still attributed to the abrasive wear even under the solid lubricating effect of SCFs. Nevertheless, the wear morphologies of the epoxy composite tested under different normal loads clearly point out that the incorporation of SCFs is an effective way to reduce the abrasive and fatigue wear of the epoxy composites during the prolonged sliding contact with the steel pin.

Figure 9(a) shows the friction coefficients of the epoxy composites with different SCF contents slid against the Cr6 steel ball of $6 \mathrm{~mm}$ in diameter for about 40,000 laps at a sliding speed of $3 \mathrm{~cm} / \mathrm{s}$ under normal loads of 2 and $6 \mathrm{~N}$. The mean friction coefficients of the epoxy slid against the $6 \mathrm{~mm}$ steel ball under the normal loads of 2 and $6 \mathrm{~N}$ (Fig. 9(a)) are about 0.71 and 0.68 , respectively, which are slightly higher than those of the one tested against the inclined 
steel pin under the same normal loads (Fig. 4(a)). It indicates that the geometry of the counterpart has a significant influence on the friction coefficient of the epoxy because the larger contact area between the steel ball and epoxy compared to that between the inclined pin and epoxy gives rise to the higher friction coefficient of the epoxy during the sliding. In Fig. 9(a), the increased SCF content from 2.5 to $20 \mathrm{wt} \%$ significantly decreases the mean friction coefficients of the epoxy composites slid against the steel ball from about 0.24 to 0.18 for the normal load of $2 \mathrm{~N}$ and from about 0.53 to 0.24 for the normal load of $6 \mathrm{~N}$, which is in agreement with the results reported in Fig. 4(a). The epoxy slid against the steel ball under the both normal loads (Fig. 9(a)) exhibits the higher friction coefficients than the one tested against the inclined pin under the same normal loads (Fig. 4(a)). However, the friction coefficients of the epoxy composites slid
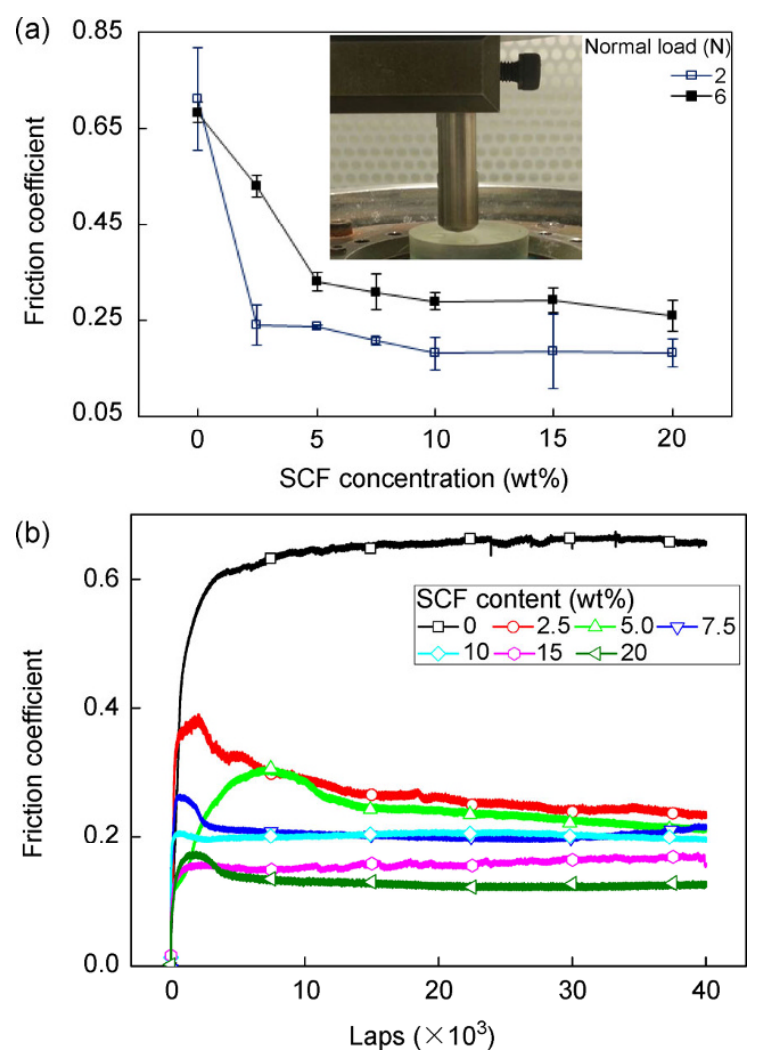

Fig. 9 (a) Friction coefficient of epoxy composites, slid against a Cr6 steel ball of $6 \mathrm{~mm}$ in diameter in a circular path of $3 \mathrm{~mm}$ in diameter for about 40000 laps at a sliding speed of $3 \mathrm{~cm} / \mathrm{s}$ under different normal loads, as a function of SCF content. (b) Friction coefficient of the same samples, measured under a normal load of $2 \mathrm{~N}$, as a function of the number of laps. The inset in (a) shows a photograph of a holder with a steel ball. against the steel ball (Fig. 9(a)) are slightly lower for all the SCF contents compared to those of the ones tested against the inclined pin (Fig. 4(a)) because the higher surface roughness of the epoxy composite caused by the protruded SCFs and SCF debonded sites than that of the epoxy (Fig. 1) gives rise to more interaction between the inclined pin and composite. The results clearly confirm that the incorporation of SCFs effectively decreases the friction coefficients of the epoxy composites slid against the both inclined pin and steel ball with a more effective influence on the friction coefficients of the composites slid against the steel ball.

Figure 9(b) presents the friction coefficients of the epoxy composites with different SCF contents, slid against the steel ball under a normal load of $2 \mathrm{~N}$, as a function of the number of laps. The friction coefficient of the epoxy slid against the steel ball reaches 0.59 after 3,000 laps and becomes stable for the rest as a result of the stable wear during the entire sliding. However, the same epoxy slid against the inclined pin exhibits a linear increase in the friction coefficient with increased laps due to the promoted wear of the epoxy with prolonged sliding (Fig. 4(a)), which indicates the geometric effect of the counterpart on the friction coefficient of the epoxy. In Fig. 9(b), the friction coefficient of the epoxy composites slid against the steel ball apparently decreases throughout the experiment with increased SCF content. Normally, a contact between a sharp tip and a sample during sliding induces a cutting state between them, which results in an apparent removal of materials from the sample surface $[53,54]$. It is supposed that the V-shaped geometry of the inclined pin can generate the higher wear of the epoxy composite by inducing a cutting state between the inclined pin and composite compared to the spherical-shaped geometry of the steel ball so that the epoxy composite slid against the inclined pin needs longer time to reach a stable wear condition $[29,30]$. Therefore, the epoxy composites slid against the steel ball (Fig. 9(b)) mostly exhibit shorter running-in period and longer stable wear period on the trends of friction coefficient versus laps than the ones tested against the inclined pin (Fig. 4(b)).

Figure 10 illustrates the wear widths and depths of the epoxy composites with different SCF contents slid 


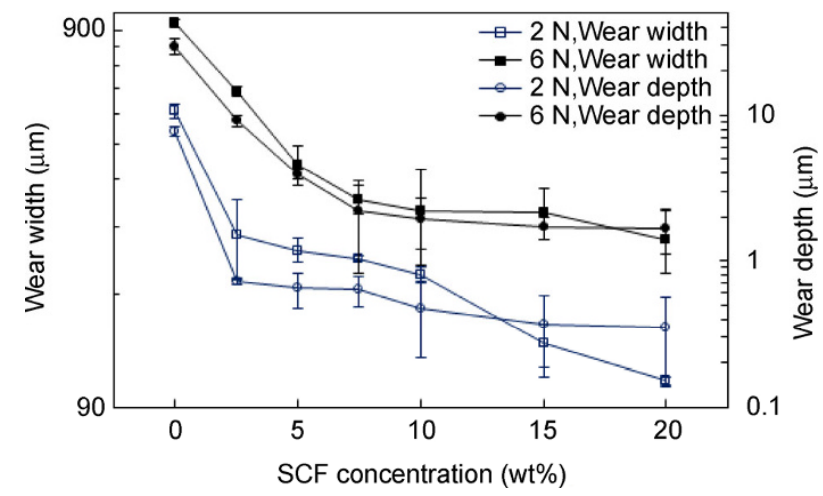

Fig. 10 Wear width and depth of epoxy composites, tested under the same conditions as described in Fig. 9, as a function of SCF content.

against the steel ball under different normal loads. It is consistently found that the wear of the epoxy composites slid against the steel ball apparently decreases with increased SCF content due to the solid lubricating effect of SCFs along with the improved hardness and elastic modulus of the composites as the wear of the epoxy composites is higher for the higher normal load [21-25, 40, 46-50]. The wear widths of the epoxy composites slid against the steel ball (Fig. 10) are apparently larger than those of the ones tested against the inclined pin (Fig. 5) due to the larger interacting area between the steel ball and composite during the sliding. However, the wear depths of the epoxy composites slid against the steel ball are significantly smaller because the inclined pin enables the removal of materials from the deeper region via a cutting state between the inclined pin and composite than the steel ball $[53,54]$.

The surface morphologies and topographies of the epoxy slid against the steel ball under the normal loads of 2 and $6 \mathrm{~N}$ are presented in Fig. 11, from which it is clearly found that the sliding of the steel ball apparently generates wear on the epoxy surface with a larger wear track for the higher normal load. The micro-wave features on the wear tracks of the epoxy tested under the both normal loads (Figs. 11(b) and 11(d)) indicate that the repeated sliding of the steel ball causes surface fatigue of the epoxy through the initiation and propagation of micro-cracks into the subsurface [51, 52].

In Fig. 12, the wear tracks of the epoxy composite with $20 \mathrm{wt} \%$ SCFs slid against the steel ball under the
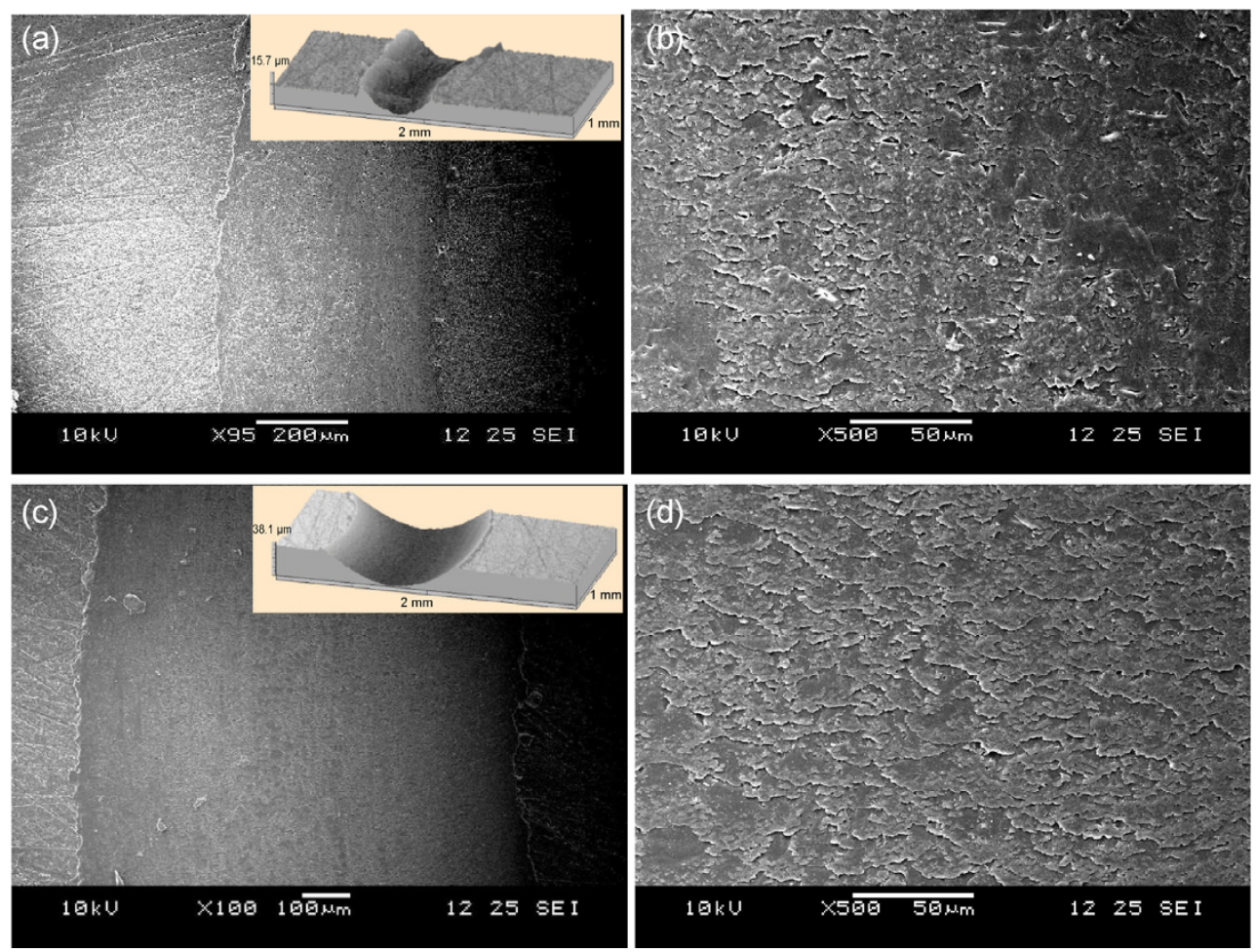

Fig. 11 SEM micrographs showing surface morphologies of worn epoxy, slid against a Cr6 steel ball of 6 mm in diameter in a circular path of $3 \mathrm{~mm}$ in diameter for about 40000 laps at a sliding speed of $3 \mathrm{~cm} / \mathrm{s}$ under normal loads ((a) and (b)) 2 and ((c) and (d)) $6 \mathrm{~N}$, observed at different magnifications. The insets in (a) and (c) show surface topographies of the same samples measured using surface profilometry. 

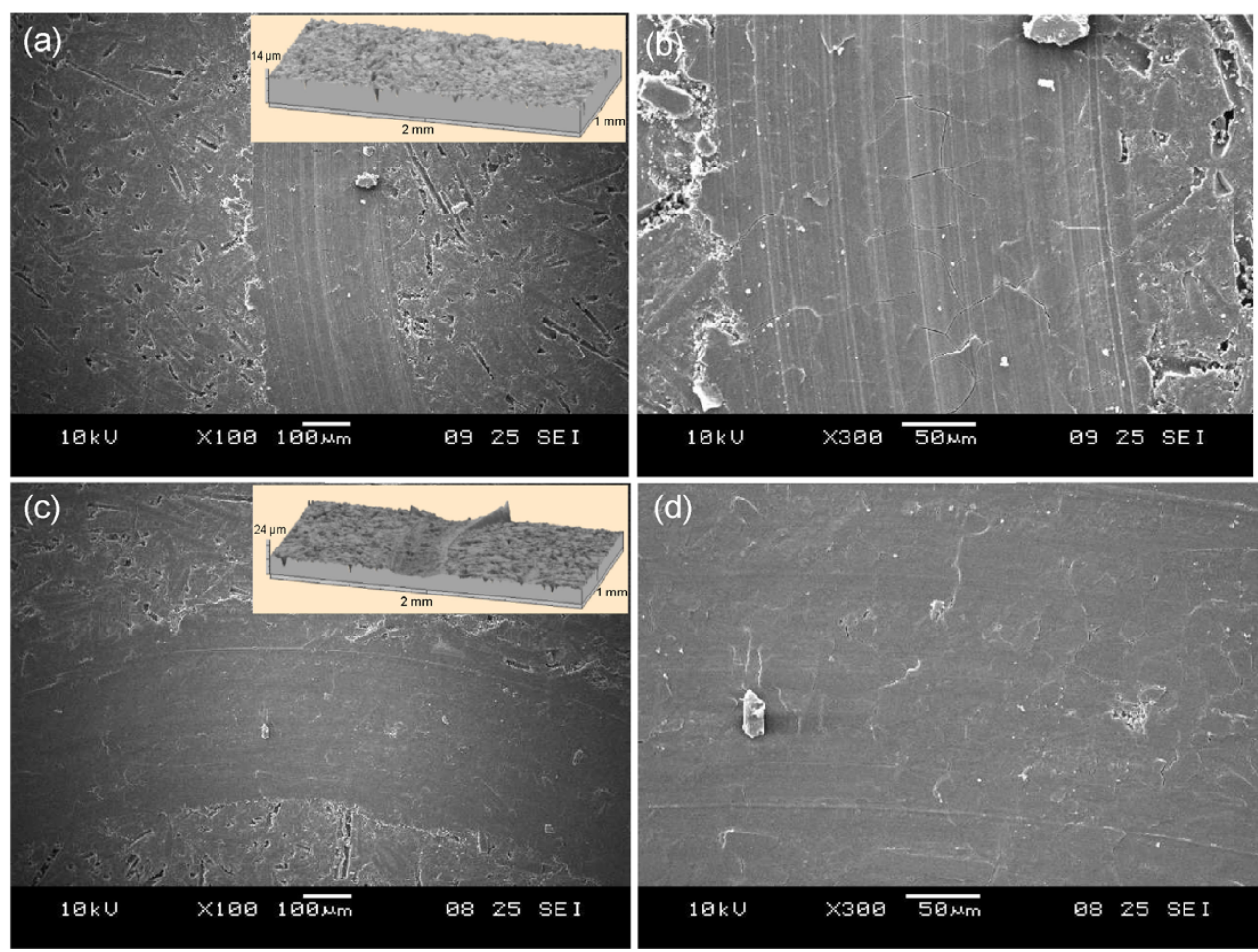

Fig. 12 SEM micrographs showing surface morphologies of worn epoxy composite with $20 \mathrm{wt} \%$ SCFs, slid against a Cr6 steel ball of $6 \mathrm{~mm}$ in diameter in a circular path of $3 \mathrm{~mm}$ in diameter for about 40000 laps at a sliding speed of $3 \mathrm{~cm} / \mathrm{s}$ under normal loads ((a) and (b)) 2 and ((c) and (d)) $6 \mathrm{~N}$, observed at different magnifications. The insets in (a) and (c) show surface topographies of the same samples measured using surface profilometry.

normal loads of 2 and $6 \mathrm{~N}$ are not as significant as those of the epoxy tested under the same normal loads (Fig. 11), which is an indication of the greatly decreased wear of the epoxy composite with the incorporation of $20 \mathrm{wt} \% \mathrm{SCFs}$. The micro-wave features caused by surface fatigue are not found on the wear tracks of the epoxy composite tested under the both normal loads (Figs. 12(b) and 12(d)) as a result of the incorporation of SCFs. However, micro-cracks formed at the SCF/matrix interfaces still can be found on the wear tracks of the epoxy composite, which is in agreement with the reports made in Figs. 8(b) and 8(d). The SEM observation clearly confirms that the incorporation of SCFs greatly reduces the wear of the epoxy composites slid against the steel ball.

\section{Conclusions}

In this study, the tribological properties of the epoxy composites with different SCF contents were systematically investigated. The increased SCF content significantly increased the hardness and Young's modulus of the epoxy composites as a result of the incorporation of rigid SCFs. The friction coefficient and wear of the epoxy composites slid against the steel pin inclined at $45^{\circ}$ to a vertical axis and steel ball dramatically decreased with increased SCF content due to the solid lubricating effect of the SCFs along with the improved hardness and elastic modulus of the composites. The SEM observation showed that the epoxy composites had less sensitivity to surface fatigue than the epoxy because the existence of SCFs on the surface lessened a direct contact between the counterpart and composite under cyclic loading. It could be concluded that the incorporation of SCFs was an effective way to improve the mechanical and tribological properties of the epoxy composites.

\section{Acknowledgement}

The authors would like to acknowledge the financial support from the Materials Innovation for Marine and 
Offshore (MIMO) Program with the grant numbers of SERC1123004028 and SERC1123004032 under the Agency for Science, Technology and Research (A*Star) of Singapore.

Open Access: This article is distributed under the terms of the Creative Commons Attribution License which permits any use, distribution, and reproduction in any medium, provided the original author(s) and source are credited.

\section{References}

[1] Sayed A A E, Sherbiny M G E, Ezz A S A E, Aggag G A. Friction and wear properties of polymeric composite materials for bearing applications. Wear 184: 45-53 (1995)

[2] Lina A D, Kuang J H. Dynamic interaction between contact loads and tooth wear of engaged polyamide gear pairs. Int $J$ Mech Sci 50: 205-213 (2008)

[3] Rabinowics E. Friction and Wear of Materials, $2^{\text {nd }}$ Ed. New York: Wiley, 1995.

[4] Friedrich K, Zhang Z, Schlarb A K. Effects of various fillers on the sliding wear of polymer composites. Compos Sci Technol 65: 2329-2343 (2005)

[5] Khun N W, Liu E. Thermal, mechanical and tribological properties of polycarbonate/ acrylonitrile-butadiene-styrene blends. J Poly Eng 33: 535-543 (2013)

[6] Ajayan P M. Single-walled carbon nanotube polymer composites: Strength and weakness. Adv Mater 12: 750-753 (2000)

[7] Thostenson E T. Advances in the science and technology of carbon nanotubes and their composites: A review. Compos Sci Technol 61: 1899-1912 (2001)

[8] Novoselov K S. Electric filed effect in atomically thin carbon films. Science 306: 666-669 (2004)

[9] Quan H, Zhang B, Zhao Q, Yuen R K K, Li R K Y. Facile preparation and thermal degradation studies of graphite nanoplatelets (GNPs) filled thermoplastic polyurethane (TPU) nanocomposites. Compos Part A 40: 1506-1513 (2009)

[10] Zhong Y J, Xie G Y, Sui G X, Yang R. Poly(ether ether ketone) composites reinforced by short carbon fibers and zirconium dioxide nanoparticles: Mechanical properties and sliding wear behavior with water lubrication. J Appl Poly Sci 119: 1711-1720 (2011)

[11] Bhattacharya S K. Metal Filled Polymers. New York (USA): Marcel Dekker Inc., 1986.

[12] Matejka L. Amine cured epoxide networks: Formation, structure and properties. Macromolecules 33: 3611-3619 (2000)

[13] Oliver W C, Pharr G M. An improved technique for determining hardness and elastic modulus using load and displacement sensing indentation experiments. J Mater Res 7: 1564-1583 (1992)

[14] Wang Z Z, Gu P, Zhang Z. Indentation and scratch behavior of nano- $\mathrm{SiO}_{2}$ /polycarbonate composite coating at micro/nano scale. Wear 269: 21-25 (2010)

[15] Khun N W, Troconis B C R, Frankel G S. Effects of carbon nanotube content on adhesion strength and wear and corrosion resistance of epoxy composite coatings on AA2024-T3. Prog Organ Coat 77: 72-80 (2014)

[16] Barrera E V. Key methods for developing single-wall nanotube composites. J Miner Met Mater Soc 52(11): A38-42 (2000)

[17] Terrones M. Science and technology of the twenty-first century: synthesis, properties and applications of carbon nanotubes. Annu Rev Mater Rec 33: 419-501 (2003)

[18] Chang L, Zhang Z, Ye L, Friedrich K. Tribological properties of epoxy nanocomposites: III, Characteristics of transfer films. Wear 262: 699-706 (2007)

[19] Archard J F. The temperature of rubbing surfaces. Wear 2: 438-455 (1959)

[20] Ashby M F, Abulawi J, Kong H S. Temperature maps for frictional heating in dry sliding. Tribol Trans 34: 577-587 (1991)

[21] Chen W X, Li B, Han G, Wang L Y, Tu J P, Xu Z D. Tribological behavior of carbon nanotube filled PTFE composites. Tribol Lett 15: 275-278 (2003)

[22] Zhang L C, Zarudi I, Xiao K Q. Novel behavior of friction and wear of epoxy composites reinforced by carbon nanotubes. Wear 261: 806-811 (2006)

[23] Li C, Chou T W. Elastic moduli of multi-walled carbon nanotubes and the effect of van der Waals forces. Compos Sci Technol 63: 1517-1524 (2003)

[24] Chen W X, Tu J P, Xu Z D, Chen W L, Zhang X B, Cheng D H. Tribological properties of Ni-P-multiwalled carbon nanotubes electroless composite coating. Mater Lett 57: 1256-1260 (2003)

[25] Wang C, Xue T, Dong B, Wang Z, Li H L. Polystyrenearcylonitrile-CNTs nanocomposite preparations and tribological behavior research. Wear 265: 1923-1926 (2008)

[26] Mate C M. Tribology on the Small Scale: A Bottom up Approach to Friction, Lubrication and Wear, $1^{\text {st }}$ Ed. New York (USA): Oxford University Press, 2008.

[27] Ronkainen H, Laukkanen A, Holmberg K. Friction in a coated surface deformed by a sliding sphere. Wear 263: 1315-1323 (2007) 
[28] Blau P J. Friction Science and Technology. New York: Marcel Dekker, 1996.

[29] Bhushan B. Tribology and Mechanics of Magnetic Storage Device, $2^{\text {nd }}$ edition. New York: Springer-Verleg, 1996.

[30] Chen G X, Kim H S, Park B H, Yoon J S. Multiwalled carbon nanotubes reinforced nylon 6 composites. Polymer 47: 4760-4767 (2006)

[31] Moniruzzaman M, Winey K I. Carbon nanotubes reinforced nylon-6 composite prepared by simple melt-compounding. Macromolecules 39: 5194-5205 (2006)

[32] Benedict L X, Louie S G, Cohen M L. Heat capacity of carbon nanotubes. Solid State Commun 100: 177-180 (1996)

[33] Berber S, Kwon Y K, Tomanek D. Unusually high thermal conductivity of carbon nanotubes. Phys Rev Lett 84: 46134616 (2000)

[34] Hone J, Llaguno M C, Biercuk M J, Johnson A T, Batlogg B, Benes Z, Fischer J E. Thermal properties of carbon nanotubes and nanotube-based materials. Appl Phys A 74: 339-343 (2002)

[35] Kasai T, Fu X Y, Rigney D A, Zharin A L. Applications of a non-contacting Kelvin probe during sliding. Wear 225-229: 1186-1204 (1999)

[36] Svahn F, Rudolphi A K, Wallen E. The influence of surface roughness on friction and wear of machine element coating. Wear 254: 1092-1098 (2003)

[37] Menezes P L, Kishore, Kailas S V. Influence of surface texture and roughness parameters on friction and transfer layer formation during sliding of aluminium pin on steel plate. Wear 267: 1534-1549 (2009)

[38] Barrett T S, Stachowiak G W, Batchelor A W. Effect of roughness and sliding speed on the wear and friction of ultra-high molecular weight polyethylene. Wear 153: 331350 (1992)

[39] Clerico M, Patierno V. Sliding wear of polymeric composites. Wear 53: 279-301 (1979)

[40] Zhang L C, Mylvaganam K, Xiao K Q. The intrinsic frictional property of carbon nanotubes. Adv Mater Res 32: $1-4$ (2008)

[41] Khun N W, Zhang H, Yang J L, Liu E. Mechanical and tribological properties of epoxy composites modified with microencapsulated mixture of wax lubricant and multiwalled carbon nanotubes. Friction 1(4): 341-349 (2013)

[42] Snow A W, Buckley L J. Fluoromethylene cyanate ester resins. Synthesis, characterization, and fluoromethylene chain length effects. Macromolecules 30: 394-405 (1997)

[43] Sung I H, Lee H S, Kim D E. Effect of surface topography on the frictional behavior at the micro/nano-scale. Wear $\mathbf{2 5 4}$ 1019-1031 (2003)

[44] Khun N W, Zhang H, Yang J L, Liu E. Tribological performance of silicone composite coatings filled with waxcontaining microcapsules. Wear 296: 575-582 (2012)

[45] Khun N W, Frankel G S, Zimmerman J. Investigation of surface morphology, wear resistance and adhesiveness of AA6061-T6 treated in a hexafluorozirconic acid based solution. Corrosion 69: 259-267 (2013)

[46] Raju B R, Suresha B, Swamy R P, Bharath K N. The effect of silicon dioxide filler on the wear resistance of glass fabric reinforced epoxy composites. Adv Polym Sci Technol: Internal J 2(4): 51-57 (2012)

[47] Thorp J M. Abrasive wear of some commercial polymers. Tribol Internat 15: 59-68 (1982)

[48] Myshkin N K, Petrokovets M I, Kovalev A V. Tribology of polymers: Adhesion, friction, wear, and mass-transfer. Tribol Internat 38: 910-921 (2005)

[49] Bahadur S. The development of transfer layers and their role in polymer tribology. Wear 245: 92-99 (2000)

[50] Khun N W, Liu E. Tribological behavior of polyurethane immersed in acidic solution. Tribo Trans 55: 401-408 (2012)

[51] Xing X S, Li R K Y. Wear behavior of epoxy matrix composites filled with uniform sized sub-micron spherical silica particles. Wear 256: 21-26 (2004)

[52] Durand J M, Vardavoulias M, Jeandin M. Role of reinforcing ceramic particles in the wear behaviour of polymer-based model composites. Wear 181-183: 833-839 (1995)

[53] Wang Y, Lim S, Luo J L, Xu Z H. Tribological and corrosion behaviors of $\mathrm{Al}_{2} \mathrm{O}_{3}$ /polymer nanocomposite coatings. Wear 260: 976-983 (2006)

[54] Yan Y D, Sun T, Liang Y C, Dong S. Effects of scratching directions on AFM-based abrasive abrasion process. Tribol Int 42: 66-70 (2009) 


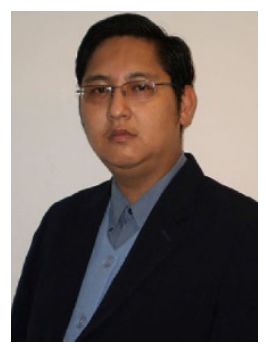

Nay Win KHUN. He received his MS degree in "Mechanics and Processing of Materials" in 2006 and his PhD degree in "Thin Films' Physics and Electrochemistry" in 2011, both

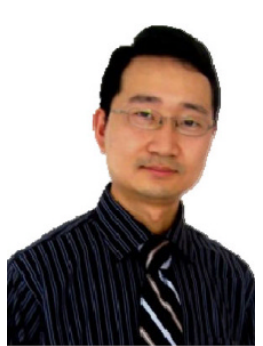

Jinglei YANG. He received his Bachelor and Master degrees in Solid Mechanics from the University of Science and Technology of China, and PhD degree in Materials Science from the University of Kaiserslautern, Germany. He joined the School of from the Nanyang Technological University, Singapore. His research interests include thin films and coatings, composite materials, corrosion, tribology and surface and interface.

Mechanical and Aerospace Engineering at Nanyang Technological University in 2008. His current position is an assistant professor. His research areas cover bio-inspired multifunctional smart materials, FRP composites and nanocomposites, ceramics, and their mechanical, dynamic, and tribological performances. 